\title{
Angiocentric Glioma: The Infiltrative Glioma with Ependymal Differentiation
}

\author{
Ayca ERSEN ${ }^{1}$, M. Serefettin CANDA ${ }^{1}$, Suleyman MEN² ${ }^{2}$ Kemal YUCESOY ${ }^{3}$, Orhan KALEMCl ${ }^{3}$, Tulay CANDA ${ }^{1}$
}

Departments of ${ }^{1}$ Pathology, ${ }^{2}$ Radiology and ${ }^{3}$ Neurosurgery, Dokuz Eylül University, Faculty of Medicine, IZMIR, TURKEY

\begin{abstract}
Angiocentric glioma is an epileptogenic, infiltrative, low grade glial tumor, with ependymal and astrocytic differentiation, most commonly seen in young adults and the pediatric age group. Herein we report a case of 21-year-old male patient who presented with fever and pharmaco-resistant seizures. Computed tomography revealed an iso-dense mass lesion in the gyrus rectus of the left frontal lobe.On magnetic resonance imaging the mass was hyperintense on both T1- and T2-weighted images with no contrast enhancement. Histopathological examination revealed monomorphous tumor cells diffusely infiltrating the neuropil with circumferential, radial, or longitudinal angiocentric alignment and subpial aggregation with perpendicular alignment of the cells to the pial surface. Among central nervous system tumors with ependymal differentiation, this distinct entity is the one with an infiltrating growth pattern. In spite of the infiltrating pattern, it does not seem to have a potential for aggressive behavior.
\end{abstract}

Key Words: Central nervous system neoplasms, Glioma, Ependymal, Seizure

\section{INTRODUCTION}

Angiocentric glioma (AG) is an epileptogenic, low grade glial tumor most commonly seen in young adults and the pediatric age group $(1,2)$. Monomorphous angiocentric glioma was first described by Wang et al. (2) in 2002. It is accepted as a Grade I, distinct entity in the current World Health Organization (WHO) classification of Central Nervous System (CNS) tumors (3). It is most commonly seen supratentorially $(2,4)$. The tumoral cells reveal both astrocytic and ependymal differentiation shown either by immunohistochemistry or electron microscopy (EM) analysis $(1,5)$. Since it is a rarely seen tumor, we present a case of AG (ICD-O 9431/1, WHO Grade I) with the review of the literature.

\section{CASE REPORT}

A 21-year-old male patient was admitted to the emergency room with fever. He had generalized tonic-clonic seizures during his stay at the hospital. The etiology of the fever could not be found but it disappeared soon after antipyretic injection. Unfortunately his seizures were unresponsive to pharmacotherapy. Neuro-imaging with computed tomography (CT) and magnetic resonance imaging (MRI) revealed a mass lesion with a size of $20 \mathrm{~mm}$ by $8 \mathrm{~mm}$ in the gyrus rectus of the left frontal lobe (Figure 1A-D). On CT (Figure 1D), the mass was iso-dense to the adjacent parenchyma except for the central foci of calcification.

(Turk Patoloji Derg 2017, 33:251-255)

Received : 25.03.2014 Accepted : 24.04.2014
On MRI, the mass was hyperintense on both T1- and T2weighted images (Figures 1A-C), and showed no contrast enhancement. There was no vasogenic edema or mass effect extending beyond the contours of the lesion.

Following complete resection, histopathological examination revealed monomorphous tumor cells diffusely infiltrating the neuropil with circumferential, radial, or longitudinal angiocentric alignment (Figure 2A,C) and subpial aggregation with perpendicular alignment of the cells to the pial surface.

Immunohistochemically, the tumor cells were diffusely GFAP-positive (Figure 2B) and they revealed intracytoplasmic dot-like or spherical EMA positivity (Figure 2D). The neurofilament positive axons among the tumor cells showed the infiltrative pattern of the tumor. Neuronal markers did not reveal any staining of the tumor cells. No mitosis or necrosis was seen and the KI67 labeling index was low. No recurrence is noted within 4 years of follow-up.

\section{DISCUSSION}

Angiocentric glioma (AG) has been included as a distinct entity in the 2007 WHO classification of CNS tumors based on the clinical and histopathological findings obtained in three studies of large series with 26 patients (3). The total number of reported cases in the English literature is currently still less than $50(2,4-21)$. It is most commonly

Correspondence: Ayça ERSEN

Dokuz Eylül Üniversitesi Tip Fakültesi, Patoloji Anabilim Dalı,

İnciralt1, 35340, İZMİR, TURKEY

E-mail: aycaersen@gmail.com Phone: +90 2324123401 
encountered in early adulthood or childhood but a few late onset cases have also been reported (12,13-21).

AGs are located superficially, most commonly in the frontoparietal cortex and temporal lobe as well as the hippocampal region. One case in the midbrain (20) and one in the thalamus (11) have also been reported. The clinical presentation is with long-standing intractable epileptic seizures $(5,19,22)$. Seizures are completely cured by surgical excision. There are also few cases presenting only with headache $(7,21)$ or dizziness (18).

Radiologically, an infiltrative non-contrast enhancing cortical tumor showing a high signal on both T1- and T2weighted images represent the findings seen both in our case and in those reported previously $(11,16,22)$. Calcification, which is a rather infrequent finding in $A G$, was also noted in our case. As a sensitive detector of calcification, CT would be a valuable tool in the diagnostic work up of these patients. Hyperintensity on both sequences helps radiologically differentiation from other low-grade tumors such as dysembrioplastic neuroepithelial tumors.

Histologically AG is composed of perivascularly arranged glial cells with both ependymal and astrocytic differentiation. The radial angiocentric alignment is a typical finding of this tumor. Perpendicular arrangement to the pial surface is another helpful feature $(1,2,23)$. Vasculocentric architecture may also be prominent in smear preparations during intraoperative consultation (24). There are 6 cases in the literature with associating cortical dysplasia $(6,14)$.

The differential diagnosis includes ependymoma, diffuse astrocytoma and pilomyxoid astrocytoma. Ependymomas have common features with AG-like pseudorosette formation resembling an angiocentric growth pattern and immunohistochemical intracytoplasmic dot-like or spherical EMA staining. However, AG is a cortical
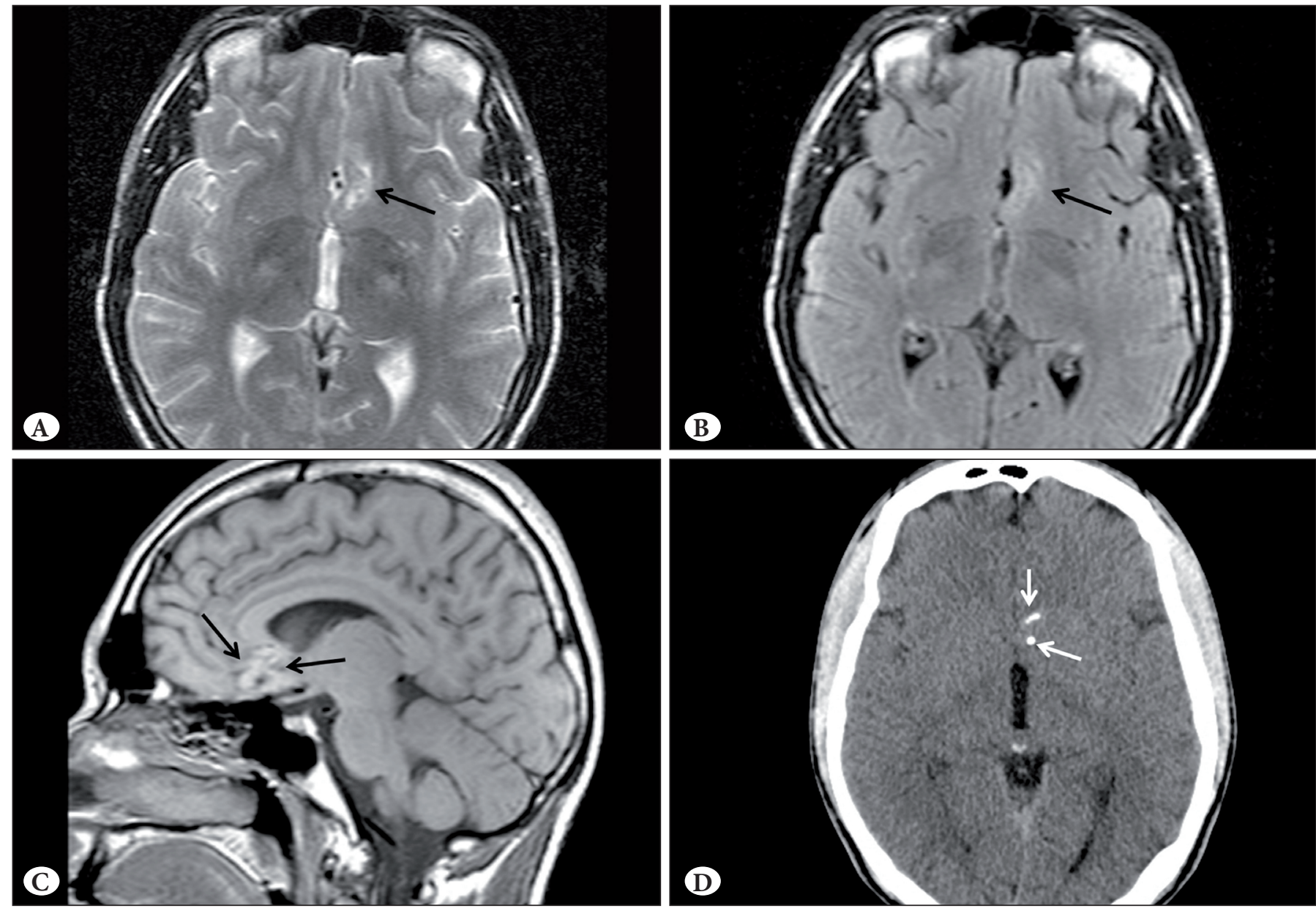

Figure 1: A,B) Transverse T2 and FLAIR weighted image shows a heterogenously hyperintense mass lesion (arrow) in the left gyrus rectus of the left frontal lobe. The abnormal signal is limited to the lesion itself with no associated vasogenic edema. C) Sagittal T1weighted image shows that mass (arrows) is slightly hyperintense relative to the brain parenchyma. D) Foci of calcification (arrows) within the mass are noted on the plain computed tomography image. 

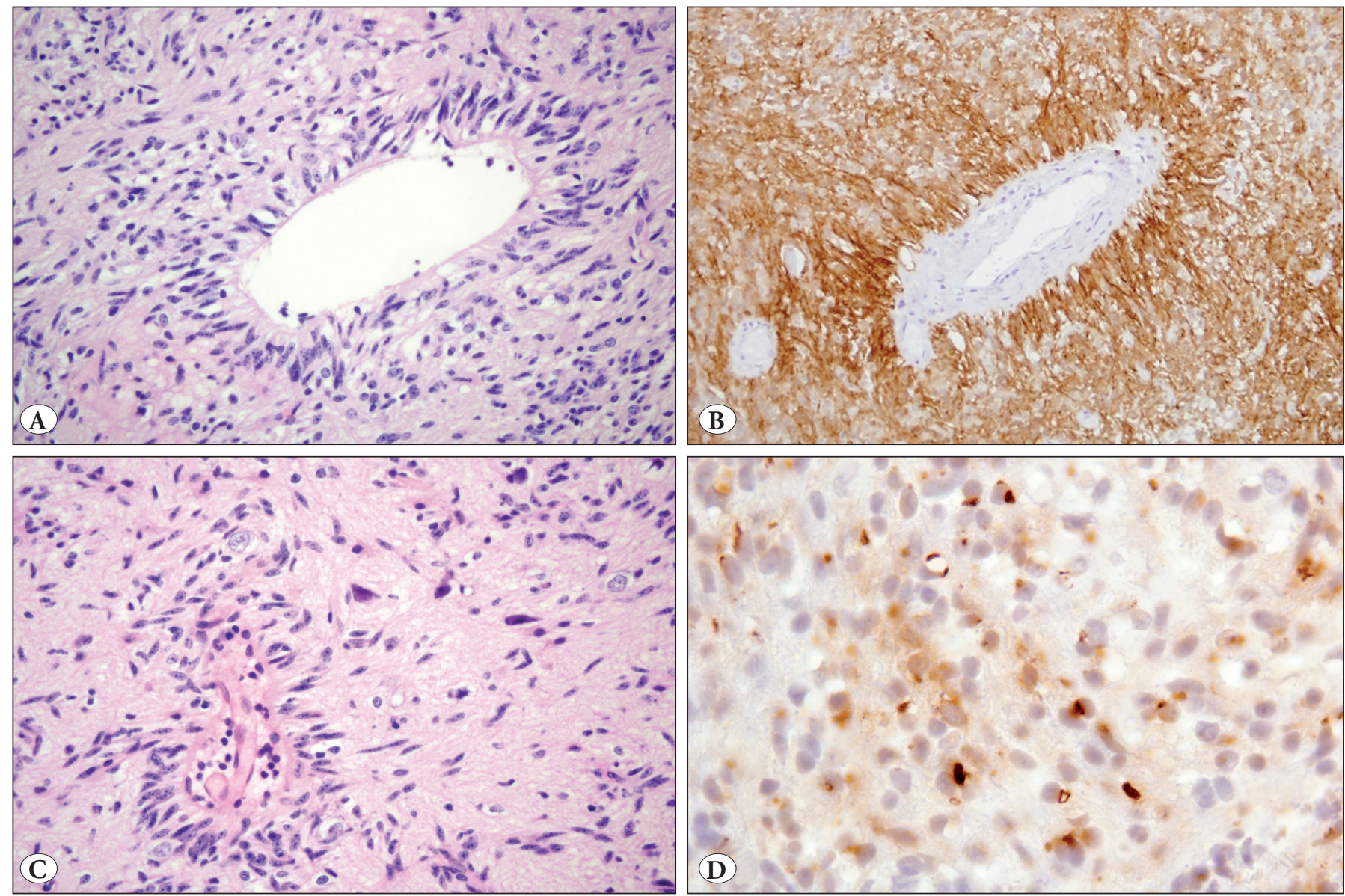

Figure 2: A) Monomorphous bipolar tumor cells make a radial arrangement around the blood vessels (H\&E; x400). B) Tumor cells show diffuse GFAP positivity (GFAP; x400). C) Entrapped non-neoplastic neuronal cells, a feature supporting the infiltrative growth pattern, should not be misinterpreted as a component of the tumor (H\&E; $\mathrm{x} 400)$. D)Perinuclear dot-like or spherical EMA staining is an evidence of the ependymal differentiation (EMA; x1000).

lesion with infiltrative growth pattern unlike expansively growing ependymomas. Diffuse astrocytoma is in the differential due to the infiltrative pattern and diffuse GFAP immunopositivity. However, no EMA staining is expected, and no angiocentric arrangement of tumor cells is seen. Pilomyxoid astrocytomas are composed of bipolar spindled tumor cells with a vasculocentric arrangement. However, it is a non-infiltrating tumor and prominent myxoid stroma is a common feature that is not seen in AGs.

There is also one study that evaluates the presence of the IDH1 R132H mutation in AG cases (9). All of 3 cases in this study were negative for the presence of IDH1 R132H mutant protein. Spontaneous mutations of IDH1 have been detected in diffuse and anaplastic astrocytomas, oligoastrocytomas, oligodendrogliomas and secondary glioblastomas (25), but are rare in primary glioblastoma and absent in ependymoma. This finding may be helpful in distinguishing this unique neoplasm from diffuse glioma.
The immunohistochemical analysis showed both ependymal and astrocytic features of the tumor cells that was also supported by ultrastructural analysis revealing intracellular ciliated lumina with microvilli, intercellular zonula adherens contacts and/or astrocyte-like intermediate filaments in the processes and the cell body $(1,2)$. A very similar tumor with only additional neuronal cell component was described as angiocentric neuroepithelial tumor (ANET) by LellouchTubiana et al. (26). However, it is not included in the current WHO classification and the current WHO working group have reached a consensus that neoplastic cells of AG do not stain with neuronal markers.

Most of the reported cases have shown low proliferative activity. Necrosis and vascular endothelial proliferation has never been encountered. The clinical follow-up of the cases has shown indolent biological behavior except for a few cases with high mitotic count $(2,13)$. The tumor has therefore been accepted as Grade I. The few cases exhibiting 
recurrence or causing mortality were argued to have either AG with anaplastic features, anaplastic astrocytoma with angiocentric ependymal differentiation, or AG with malignant transformation. There are also some reports of AGs with high mitotic count but showing benign behavior (16). Based upon most reported cases, the overall prognosis seems to be rather benign.

Comparative genomic hybridization analysis of a few tumors demonstrated loss of chromosomal bands 6q24-q25 and gain of 11p11.2 including PTPRJ; the pathobiological relevance of these findings for this particular tumor should also be questioned (22).

Among central nervous system tumors with ependymal differentiation, this distinct entity is the one with an infiltrating growth pattern. In spite of the infiltrating pattern, it does not seem to have a potential for aggressive behavior.

The histogenesis of angiocentric glioma is a subject of debate, whether of ependymal or radial glial cell origin. A subset of angiocentric gliomas with associating cortical dysplasia may also suggest a developmental basis for their origin.

The favorable prognosis of this rare entity requires a careful evaluation of cortical epileptogenic tumors with imaging and morphological studies.

\section{REFERENCES}

1. Brat DJ, Scheithauer BW, Fuller GN, Tihan T. Newly codified glial neoplasms of the 2007 WHO Classification of Tumours of the Central Nervous System: Angiocentric glioma, pilomyxoid astrocytoma and pituicytoma. Brain Pathol. 2007;17:319-24.

2. Wang M, Tihan T, Rojiani AM, Bodhireddy SR, Prayson RA, Iacuone JJ, Alles AJ, Donahue DJ, Hessler RB, Kim JH, Haas M, Rosenblum MK, Burger PC. Monomorphous angiocentric glioma: A distinctive epileptogenic neoplasm with features of infiltrating astrocytoma and ependymoma. J Neuropathol Exp Neurol. 2005;64:875-81.

3. Louis DN, Ohgaki H, Wiestler OD, Cavenee WK, Burger PC, Jouvet A, Scheithauer BW, Kleihues P. The 2007 WHO classification of tumours of the central nervous system. Acta Neuropathol. 2007;114:97-109.

4. Preusser M, Hoischen A, Novak K, Czech T, Prayer D, Hainfellner JA, Baumgartner C, Woermann FG, Tuxhorn IE, Pannek HW, Bergmann M, Radlwimmer B, Villagrán R, Weber RG, Hans VH. Angiocentric glioma: Report of clinico-pathologic and genetic findings in 8 cases. Am J Surg Pathol. 2007;31:1709-18.

5. Sugita $\mathrm{Y}$, Ono T, Ohshima K, Niino D, Ito M, Toda K, Baba H. Brain surface spindle cell glioma in a patient with medically intractable partial epilepsy: A variant of monomorphous angiocentric glioma? Neuropathology. 2008;28:516-20.
6. Takada S, Iwasaki M, Suzuki H, Nakasato N, Kumabe T, Tominaga T. Angiocentric glioma and surrounding cortical dysplasia manifesting as intractable frontal lobe epilepsy-case report. Neurol Med Chir (Tokyo). 2011;51:522-6.

7. Shakur SF, McGirt MJ, Johnson MW, Burger PC, Ahn E, Carson BS, Jallo GI. Angiocentric glioma: A case series. J Neurosurg Pediatr. 2009;3:197-202.

8. Rho GJ, Kim H, Kim HI, Ju MJ. A case of angiocentric glioma with unusual clinical and radiological features. J Korean Neurosurg Soc. 2011;49:367-9.

9. Raghunathan A, Olar A, Vogel H, Parker JR, Coventry SC, Debski $\mathrm{R}$, Albarracin CT, Aldape KD, Cahill DP, Powell SZ, Fuller GN. Isocitrate dehydrogenase $1 \mathrm{R} 132 \mathrm{H}$ mutation is not detected in angiocentric glioma. Ann Diagn Pathol. 2012;16:255-9.

10. Pokharel S, Parker JR, Parker JC, Coventry S, Stevenson CB, Moeller KK. Angiocentric glioma with high proliferative index: Case report and review of the literature. Ann Clin Lab Sci. 2011;41:257-61.

11. Mott RT, Ellis TL, Geisinger KR. Angiocentric glioma: A case report and review of the literature. Diagn Cytopathol. 2010;38:452-6.

12. Miyata H, Ryufuku M, Kubota Y, Ochiai T, Niimura K, Hori T. Adult-onset angiocentric glioma of epithelioid cell-predominant type of the mesial temporal lobe suggestive of a rare but distinct clinicopathological subset within a spectrum of angiocentric cortical ependymal tumors. Neuropathology. 2011;32:479-91.

13. Miyahara H, Toyoshima $\mathrm{Y}$, Natsumeda M, Uzuka T, Aoki H, Nakayama Y, Okamoto K, Fujii Y, Kakita A, Takahashi H. Anaplastic astrocytoma with angiocentric ependymal differentiation. Neuropathology. 2011;31:292-8.

14. Marburger T, Prayson R. Angiocentric glioma: A clinicopathologic review of 5 tumors with identification of associated cortical dysplasia. Arch Pathol Lab Med. 2011;135:1037-41.

15. Ma X, Ge J, Wang L, Xia C, Liu H, Li Y, He J, Zhu W. A 25-yearold woman with a mass in the hippocampus. Brain Pathol. 2010; 20:503-6.

16. Li JY, Langford LA, Adesina A, Bodhireddy SR, Wang M, Fuller GN. The high mitotic count detected by phospho-histone H3 immunostain does not alter the benign behavior of angiocentric glioma. Brain Tumor Pathol. 2012;29:68-72.

17. Koral K, Koral KM, Sklar F. Angiocentric glioma in a 4-year-old boy: Imaging characteristics and review of the literature. Clin Imaging. 2012;36:61-4.

18. Hu XW, Zhang YH, Wang JJ, Jiang XF, Liu JM, Yang PF. Angiocentric glioma with rich blood supply. J Clin Neurosci. 2010;17:917-8.

19. Fulton SP, Clarke DF, Wheless JW, Ellison DW, Ogg R, Boop FA. Angiocentric glioma-induced seizures in a 2 -year-old child. J Child Neurol. 2009;24:852-6.

20. Covington DB, Rosenblum MK, Brathwaite CD, Sandberg DI. Angiocentric glioma-like tumor of the midbrain. Pediatr Neurosurg. 2009;45:429-33.

21. Arsene D, Ardeleanu C, Ogrezeanu I, Danaila L. Angiocentric glioma: Presentation of two cases with dissimilar histology. Clin Neuropathol. 2008;27:391-5. 
22. Preusser M, Hoischen A, Novak K, Czech T, Prayer D, Hainfellner JA, Baumgartner C, Woermann FG, Tuxhorn IE, Pannek HW, Bergmann M, Radlwimmer B, Villagran R, Weber RG, Hans VH. Angiocentric glioma: Report of clinico-pathologic and genetic findings in 8 cases. Am J Surg Pathol. 2007;31:1709-18.

23. Wang M, Tihan T, Rojiani A, Bodhireddy S, Burger PC. Angiocentric bipolar astrocytoma: A distinctive infiltrating astrocytoma of children. J Neuropathol Exp Neurol. 2002;61:475.

24. Varikatt W, Dexter M, Mahajan H, Murali R, Ng T. Usefulness of smears in intra-operative diagnosis of newly described entities of CNS. Neuropathology. 2009;29:641-8.
25. Yan H, Parsons DW, Jin G, McLendon R, Rasheed BA, Yuan W, Kos I, Batinic-Haberle I, Jones S, Riggins GJ, Friedman H, Friedman A, Reardon D, Herndon J, Kinzler KW, Velculescu VE, Vogelstein B, Bigner DD. IDH1 and IDH2 mutations in gliomas. N Engl J Med. 2009;360:765-73.

26. Lellouch-Tubiana A, Boddaert N, Bourgeois M, Fohlen M, Jouvet A, Delalande O, Seidenwurm D, Brunelle F, Sainte-Rose C. Angiocentric neuroepithelial tumor (ANET): A new epilepsyrelated clinicopathological entity with distinctive MRI. Brain Pathol. 2005;15:281-6. 